\title{
HANDWRITING SPEED AND SIZE IN INDIVIDUALS WITH PARKINSON'S DISEASE COMPARED TO HEALTHY CONTROLS: THE POSSIBLE EFFECT OF CUEING
}

\author{
Mari Raudmann $^{1}$, Pille Taba ${ }^{2}$, Kadri Medijainen ${ }^{1}$ \\ ${ }^{1}$ Institute of Exercise Biology and Physiotherapy, University of Tartu, Tartu, Estonia \\ ${ }^{2}$ Department of Neurology and Neurosurgery, University of Tartu, Tartu, Estonia
}

\begin{abstract}
Changes in handwriting are common in individuals with Parkinson's disease (PD). Improving motor performance by using cueing strategies has become a standard in PD physiotherapy. The objective of the study was to identify whether using different paper types (plain, horizontal lined and grid lined) can improve handwriting of individuals with PD. 21 subjects with mild-to-moderate PD and 9 healthy control group members participated. Subjects were given the task of writing two repetitions of one simple and one complex sentence on plain, horizontal lined and grid lined paper. Handwriting speed and size were measured. Results confirm previous findings stating that individuals with PD write slower and have smaller handwriting compared to healthy controls. Based on the study, it can be concluded that writing on different types of paper does not affect writing speed, but does affect handwriting size of patients with PD.
\end{abstract}

Keywords: Parkinson's disease, handwriting speed, handwriting size, cueing

\section{INTRODUCTION}

Writing is a necessary skill in everyday activities for people in all ages. Handwriting is affected by numerous factors, one of the most important ones is writing speed. Information must be written down in a reasonable period of time, otherwise writing is not functional. For example, writing speed is important when writing tests, taking notes, messages, etc [14].

Parkinson's disease (PD) is one of the most common neurodegenerative disorders. It is characterized by motor and non-motor symptoms, includ- 
ing bradykinesia, rigidity, postural impairment, sensory dysfunction, etc [7]. Changes in handwriting are one of the clinical symptoms of PD [7]. According to previous studies $[6,8,13]$ the handwriting speed of people with $\mathrm{PD}$ is slower compared to age- and gender-matched healthy individuals and. Changes in handwriting occur prior PD is diagnosed, being one of the first symptoms of the illness [11].

Performing smooth repetitive movements, like walking or writing, is difficult for PD patients because they tend to make complex movements in separate parts [1]. Studies have shown that PD patients benefit in motor learning from cueing [5]. For example, bright parallel [12] and regular white lines [3] have been used on the walkway to improve gait.

In handwriting, different types of paper could serve as cues. Researchers have used horizontal lined paper [2,8] and grid paper [2] in their studies to improve handwriting. Nevertheless, the effect of different types of paper on handwriting remains unclear.

\section{MATERIALS AND METHODS}

\section{Subjects}

30 right-handed subjects, $21 \mathrm{PD}(70.0 \pm 4.4$ years) and 9 controls $(72.5 \pm 5.1$ years) were included in the study. PD patients, diagnosed by the Queen Square Brain Bank criteria, were randomly selected from those attending Neurology Clinic at Tartu University Hospital, Estonia. Nine healthy individuals without previous history of neurological illness or traumatic injury to the dominant hand in the last two years served as the control subjects. All subjects signed an informed consent form. Table 1 illustrates disease severity of the PD patients, characterised according to the Hoehn \& Yahr (H\&Y) and Movement Disorders Society Unified Parkinson's Disease Rating Scale (MDS-UPDRS).

Table 1. Clinical characteristics of subjects with Parkinson's disease.

\begin{tabular}{lc}
\hline Characteristic & PD $(\mathbf{n}=\mathbf{2 1})$ \\
\hline Disease duration, mean, years & $10.2 \pm 6.4$ \\
\hline H\&Y Scale & $2.3 \pm 0.5$ \\
\hline MDS-UPDRS total score & $61.4 \pm 19.7$ \\
\hline
\end{tabular}

MDS-UPDRS - Movement Disorder Society Unified Parkinson's Disease Rating Scale; PD - Parkinson's disease; H\&Y - Hoehn and Yahr Scale 


\section{METHODS}

\section{Writing assignment and handwriting analysis}

The subjects were seated at a table (height of the table $74 \mathrm{~cm}$, height of the chair $42 \mathrm{~cm}$ ) in a well lit room. Participants were asked to write on plain, horizontal lined $(0.8 \mathrm{~cm}$ apart $)$ and grid lined $(0.5 \mathrm{~cm} \times 0.5 \mathrm{~cm})$ A6 paper one simple (in Estonian: Vaalad elavad sinises ookeanis - Whales live in a blue ocean) and one complex sentence (in Estonian: Kui Arno isaga koolimajja jõudis, olid tunnid juba alanud - When Arno and his father got to the schoolhouse, classes had already started). The size of the paper was meant to imitate real-life situations (for example, taking notes or writing down messages). It was also reported by the participants of the present study that taking notes is the main reason for them to use handwriting.

Subjects performed two repetitions on all conditions, using a blue ballpoint pen. They were instructed to write as they normally do. Duration of writing (defined as writing speed in the present study) was measured with a stopwatch, the subject not being aware of it. PD subjects performed the writing assignment in the "on" state.

Word width sum was used as indicator of handwriting size and it was found subsequently: the text written on A6 papers was scanned to the computer; Foxit Reader 6.1 programme was used to measure the length of each word in centimetres. To do so, the text was enlarged to $200 \%$ in Foxit Reader software (to improve measuring accuracy). The width of each word in the sentence was measured using the distance measuring tool available in the programme and was summed up for data analysis.

\section{Statistical analysis}

Microsoft Office Excel 2007 and IBM SPSS Statistics 22.0 were used for data analysis. Data are presented as average and standard deviation. Dependent variable T-test was used to examine differences between the groups. A level of $\mathrm{p}<0.05$ was selected to indicate statistical significance. 


\section{RESULTS}

\section{Writing speed}

Healthy controls wrote both sentences significantly faster than PD subjects on all types of paper. Type of paper did not affect writing speed in neither of the groups. Results described beforehand are illustrated in Figures 1 and 2.

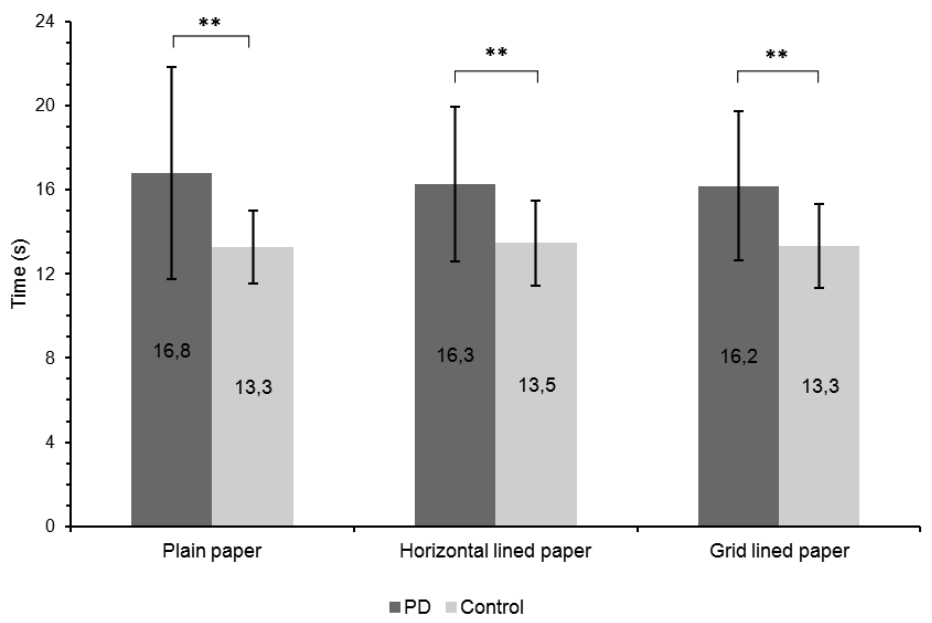

Figure 1. The average $( \pm S D)$ writing time (in seconds) on different paper types when writing simple sentences. PD - Parkinson's disease group $(n=21)$; Control control group $(n=9) ;{ }^{*} p<0.05 ;{ }^{* *} p<0.01$.

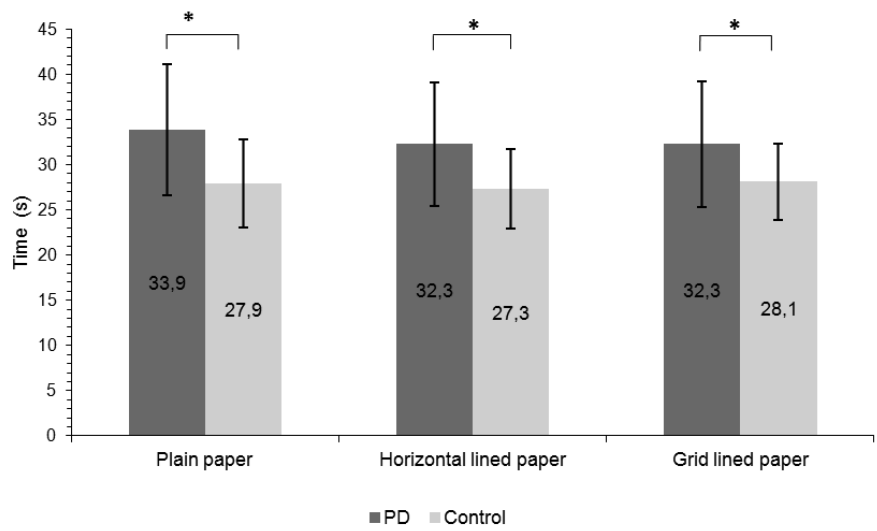

Figure 2. The average $( \pm S D)$ writing time (in seconds) on different paper types when writing complex sentences. PD - Parkinson's disease group $(n=21)$; Control - control group $(n=9) ;{ }^{*} p<0.05$. 


\section{Handwriting size}

In all conditions, the handwriting of control group subjects was statistically larger $(p<0.05)$ than the handwriting of participants with PD. When writing a simple sentence on different types of paper, the size of the handwriting of PD subjects decreased progressively. The same tendency was also present when writing a complex sentence, but the changes were not statistically significant. Some differences in handwriting size were also noticeable in the control group, but the changes were not statistically significant. Detailed results on handwriting size are presented in Figures 3 and 4.

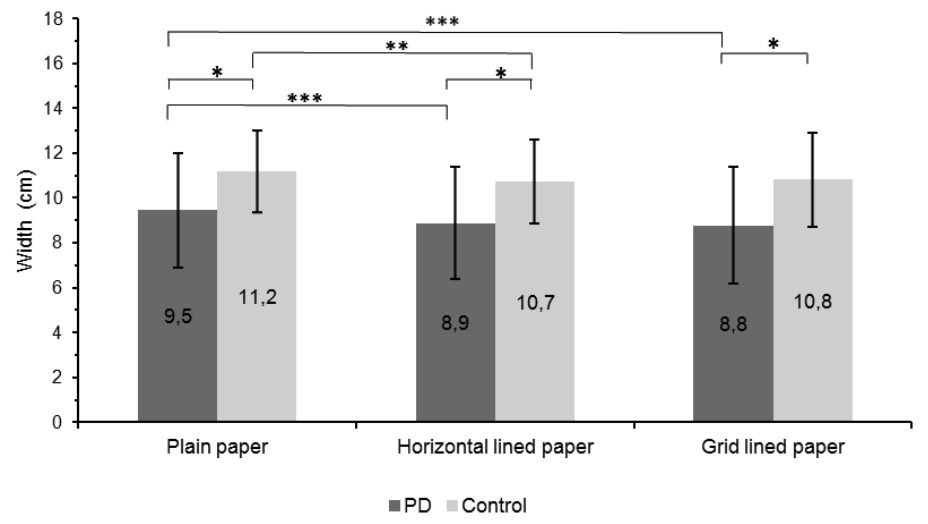

Figure 3. The average $( \pm S D)$ word width (in centimeters) on different paper types when writing simple sentences. PD - Parkinson's disease group $(n=21)$; Control control group $(n=9) ;{ }^{*} p<0.05 ;{ }^{* *} p<0.01 ;{ }^{* *} p<0.001$.

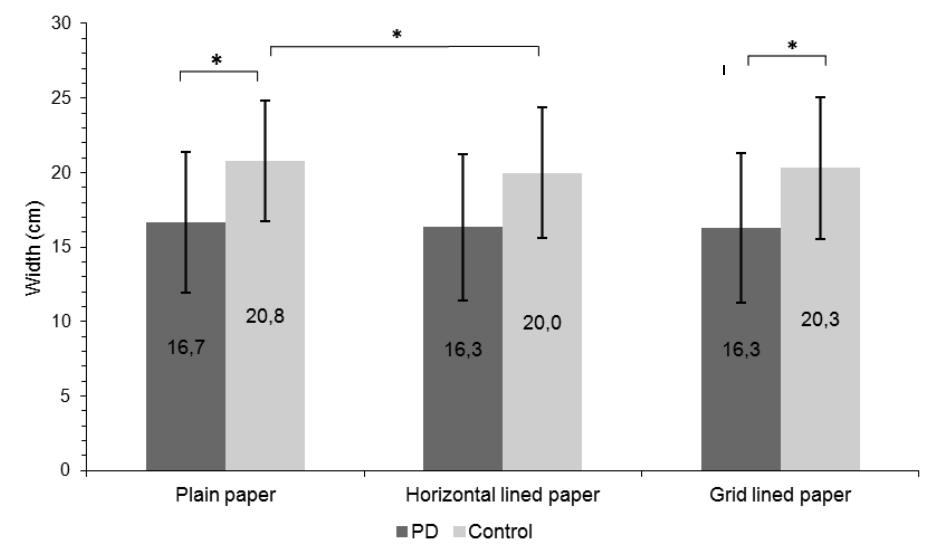

Figure 4. The average $( \pm S D)$ word width (in centimeters) on different paper types when writing complex sentences. PD - Parkinson's disease group $(n=21)$; Control control group $(n=9) ;{ }^{*} p<0.05$. 


\section{DISCUSSION}

The aim of the current study was to identify, if writing on different types of paper changes the handwriting size and speed on individuals with PD. Subjects wrote on plain, horizontal lined and grid lined A6 size paper one simple and one complex sentence. The results were compared to those of healthy individuals.

It was found that subjects with PD write smaller than healthy control group members. The results are in accordance with previous studies $[6,9$, $11,13]$. However, former studies have merely compared handwriting of PD patients and healthy controls and have not looked into different types of paper as possible cues for improving handwriting.

To our knowledge, the effect of different paper types on handwriting has been previously studied only once by Bryant and colleagues [2], however, the study mentioned differs methodically from the present study. Bryant et al. [2] tried to find out whether using grid lines (horizontal and vertical stimuli) has a greater effect on handwriting size than writing on lined paper (only horizontal stimuli). When writing on lined paper (10 mm apart), subjects were given instructions to write each letter in such a way that it "touches" the top and bottom lines. On grid paper $(10 \mathrm{~mm} \times 10 \mathrm{~mm})$ the participant had to "touch" the upper, lower, left and right lines when writing each of the letters. Participants wrote immediately after practising with parallel lines and immediately after practising with grid lines. As a result, they found that subjects who had problems with micrographia improved their handwriting size when writing on lined paper. Writing on grid paper did not further improve the size of handwriting.

Compared to Bryant et al. study [2], the subjects of the present study were not given any instructions on how to write and they were not able to practise beforehand, because the aim was to capture writing in everyday condition (not artificially created). In Bryant's study it was concluded that the addition of lines on paper decreases the handwriting size of people with PD. In their study, PD patients wrote the smallest when writing on plain paper, but they did not investigate the handwriting on plain white paper without instructions on horizontal lined and grid paper. In addition, they did not compare the results to healthy control group members. So, the results of the current study cannot be compared to Bryant's at full extent [2].

Previous studies about the effect of cueing on handwriting have come to divergent results, indicating that writing is a complex activity, where different instructions and combining multiple cues might lead to diverse effects. For example, Oliveira et al. [8] found that when PD subjects write on lined 
paper or have auditory reminders while writing, they are able to write with more normal amplitude. On the other hand, Ringenbach et al. [10] investigated the influence of different cues (visual, auditory and verbal) on drawing movements and found that auditory and verbal stimuli enhanced continuous movement making, but visual stimuli did not.

When comparing the results of previous studies and those of the current study, it could be speculated that visual horizontal lines can act as enhancing stimuli to increase handwriting size, when using specific auditory instructions. Without instructions the size of the handwriting seems to decrease, but further studies are needed to confirm our speculations.

It has to be taken into consideration that in the studies by Oliveira et al. [8] and Ringenbach et al. [10] handwriting-like movements were performed. Therefore, these studies may not give an adequate estimation about the effects of cueing on handwriting. Writing a sentence is a more complex activity with higher cognitive demands compared to drawing lines or circles. Tucha and colleagues [13] came to the same conclusion.

In addition, our study confirmed that individuals with PD write slower than healthy controls $[4,6,13]$. The writing speed was not affected by writing on different types of paper in neither of groups. Additional research is needed to draw final conclusions about the effect of cueing to handwriting speed. It is possible that what was found by Suteerawattananon et al. [12] that to improve different parameters different stimuli are needed, might also apply to handwriting. They found that auditory stimuli enhanced gait speed, but visual stimuli improved stride length [12]. To our knowledge, there are no studies that have explored the effect of different stimuli to writing speed in people with PD, but it can be hypothesized the same effect might occur.

\section{REFERENCES}

1. Bidet-Ildei C, Pollak P, Kandel S, Fraix V, Orliaguet JP. (2011) Handwriting in patients with Parkinson's disease: Effect of L-dopa and stimulation of the sub-thalamic nucleus on motor anticipation. Hum Movement Sci, 30: 783-791

2. Bryant MS, Rintala DH, Lai EC, Protas EJ (2010) An investigation of two interventions for micrographia in individuals with Parkinson's disease. Clin Rehabil, 24: 1021-1026

3. de Melo Roiz, Cacho A, Walker E, Cliquet A, Quagliato B, Aparecida EA. (2011) Analysis of parallel and transverse visual cues on the gait of individuals with idiopathic Parkinson's disease (Abstract). Int J Rehabil Res, 34: 343-348 
4. Eichhorn TE, Gasser T, Mai N, Marquardt C, Arnold G, Schwarz J, Oertel WH. (1996) Computational analysis of open loop handwriting. Movements in Parkinson's disease: a rapid method to detect dopamimetic effects. Movement Disord, 11: 289-297

5. Espay AJ, Baram Y, Dwivedi AK, Shukla R, Gartner M, Gaines L, Duker AP, Revilla FJ. (2010) At-home training with closed-loop augmented-reality cueing device for improving gait in patients with Parkinson disease. J Rehabil Res Dev, 47: 573-582

6. Lange KW, Mecklinger L, Walitza S, Becker G, Gerlach M, Naumann M, Tucha O. (2006) Brain dopamine and kinematics of graphomotor functions. Hum Movement Sci, 25: 492-509

7. Massano J, Bhatia K. (2012) Clinical approach to Parkinson's disease: features, diagnosis and principles of management. Cold Spring Harb Perspect Med, 2: 1-12.

8. Oliveira RM, Gurd JM, Nixon PN, Marshall JC, Passingham RE. (1997) Micrographia in Parkinson's disease: the effect of providing external cues. J Neurol Neurosur Ps, 63: 429-433

9. Ondo WG, Satija P. (2007) Withdrawal of visual feedback improves micrographia in Parkinson's disease. Movement Disord, 22: 2130-2131

10. Ringenbach SDR, van Gemmert AWA, Shill HA, Stelmach GE. (2011) Auditory instructional cues benefit unimanual and bimanual drawing in Parkinson's disease patients. Hum Movement Sci, 30: 770-782

11. Rosenblum S, Samuel M, Zlotnik S, Erikh I, Schlesinger I. (2013) Handwriting as an objective tool for Parkinson's disease diagnosis. J Neurol, 260: 2357-2361

12. Suteerawattananon M, Morris GS, Etnyre BR, Jankovic J, Protas EJ. (2004) Effects of visual and auditory cues on gait in individuals with Parkinson's disease. J Neurol Sci, 219: 63-69

13. Tucha O, Mecklinger L, Thome J, Reiter A, Alders GL, Sartor H, Naumann M, Lange KW. (2006) Kinematic analysis of dopaminergic effects on skilled handwriting movements in Parkinson's disease. J Neural Transm, 113: 609623

14. Van Dremt N, McCluskey A, Lannin NA. (2011) A review of factors that influence adult handwriting. Aust Occup Therap J, 58: 321-328

\section{Correspondence to:}

Mari Raudmann

Kelgumäe 47

Peetri alevik, Rae vald

75301 Harjumaa

Estonia

E-mail: mariraudmann@hotmail.com 